\title{
Fernando Berguño Hurtado, Los soldados de Napoleón en la Independencia de Chile. 1817- 1830, Santiago, RIL Editores, 2015, 343 páginas.
}

El libro de Fernando Berguño, los soldados de Napoleón en la Independencia de Chile, es el resultado de una tesis de doctorado en Historia defendida en la Escuela Práctica de Altos Estudios de París (IV Sección).

El objetivo es publicar un libro que muestra "el destino de estos generales de Napoleón que combatieron por la independencia de Chile” (p. 12).

Los soldados de Napoleón, es una obra académica producto de una larga investigación y reflexión sobre estos soldados franceses, el mérito de este libro, es situarse al margen de los estudios tradicionales que se han escrito sobre la historia militar de Chile.

Por ende, la historiografía chilena ha centrado sus investigaciones en los héroes patrios y las tropas patriotas. A diferencia de lo anterior, Fernando Berguño, sitúa su investigación en el papel y la influencia de los oficiales franceses en la independencia de Chile. De la misma manera, estudia "la introducción de métodos y conocimientos militares" (p. 21) que permiten discernir la contribución de los soldados franceses en la Academia Militar de 1817.

El título de la obra permite comprender la intención del autor, señalar que "la historia de los oficiales franceses en la guerra de la Independencia de Chile se inscribe en un doble contexto, "el de la historia napoleónica y el de la historia política y militar de Chile” (p. 24). Por lo tanto, este doble contexto, responde a aquellos soldados que emigraron a América tras la derrota de Napoleón en Waterloo, encontrando en Chile una oportunidad para continuar su carrera militar. 
Para la realización de este trabajo, Fernando Berguño Hurtado revisó diversas fuentes, la documentación existente en la Asociación de Diplomáticos de Carrera y a la Dirección de Bibliotecas, Archivos y Museos. En Francia: Service historique de l' armée de Terre (Vincennes), Quai d' Orsay, Archives Nationales (C.A.R.A.N), Bibliothéque Thiers (Fonds Masson), Bibliothéque Nationale de France (B.N.F.), Musée de la Chartreuse (Douai). En Chile: Museo Histórico Nacional, Archivo Nacional, Biblioteca Medina, Club de la Unión, Instituto O’Higginiano. En Argentina: Archivo General de la Nación, Archivo General del Ejército, Museo Mitre, Museo Nacional de Historia (Buenos Aires), Biblioteca del Círculo Militar (p.14).

De los dieciséis capítulos de este libro, creo que los más relevantes para el lector interesado en la historia de los oficiales franceses en la Independencia de Chile son los diez últimos, en el primer capítulo titulado “Génesis de la aventura francesa en las Américas”, Berguño estudia la emigración de los soldados franceses hacia las colonias españolas de América en 1815 y, sobre todo, explican las causas del exilio de estos oficiales en 1815, antecedente histórico que no se conoce y no ha sido trabajado por la historiografía chilena.

El autor señala que la "historia de los emigrados franceses de 1815 en las Américas se inserta en el contexto de la política de Napoleón hacia la América española” (p. 25). Por lo tanto, la participación de los soldados franceses responde a los ideales políticos (p. 25). La explicación de Fernando Berguño, está fundamentada por Fernand Beaucour en su libro Les soldats de Napoleon dans les guerres d'insurrection nationale, quien plantea que "la acción de estos soldados es un movimiento inspirado por las ideas de la Revolución francesa” (p. 25). Estos ideales sirvieron para mantener vivo el espíritu de las políticas del Imperio francés en América, Fernando Berguño plantea que "los antiguos soldados del Consulado y del Imperio 
no aceptaban la derrota de Waterloo, y continuaron esparciendo, aisladamente, a lo largo del mundo, los ideales de la Revolución francesa” (p. 25).

Un punto interesante de este capítulo es la explicación que entrega Fernando Berguño sobre esta migración citando la Proclama de Cambrai, del 28 de junio de 1815, firmada por el rey Luis XVIII para una reconciliación nacional (p. 28). Esta valiosa fuente contiene los motivos y los nombres de los oficiales que debían ser arrestados, de esos nombres, tres son específicamente relevantes para el ensayo del autor: los generales Clausel y Brayer, y el general Grouchy, mariscal de Francia durante los cien días (p. 28). Estos oficiales fueron los que emigraron a Chile con el propósito de continuar la carrera de las armas, aunque también hubo hombres desorientados respecto a su futuro militar por no concebir un provenir auspicioso en la Francia restaurada, entre estos oficiales se encontraban el sargento Jorge Beauchef y los tres hermanos Bruix, (32). La emigración de estos soldados franceses a América les permitió continuar su carrera militar y tener un futuro estable.

"La Expedición del Clifton" es el título que recibe el segundo capítulo del libro, Berguño narra el viaje de José Miguel Carrera a bordo del bergantín Expedición con rumbo a los Estados Unidos, donde esperaba reunir funcionarios militares para retomar el poder en Chile (p. 68) y está enfocado en el encuentro que sostiene Carrera con los generales Grouchy y Clausel. Lo interesante de este capítulo, es la conversación que sostuvo Carrera con Grouchy, donde "intercambian recuerdos y hablan de sus proyectos. Grouchy, por su parte, se muestra interesado en la idea de ir a combatir por la causa de la independencia sudamericana, un proyecto al cual pretendía asociar a sus dos hijos” (p. 69). Este punto se centra especialmente en los esfuerzos de José Miguel para que Grouchy apoye financiera y militarmente su expedición. Además, se ocupa de relatar el financiamiento que consiguió Carrera a través de Darcy y Didier para armar las cuatro naves, el Clifton, el Savage, el Davei y el Regent. El autor 
menciona el fracaso de la expedición del Clifton, el reclutamiento de los miembros y el arresto de Carrera (p. 75). Finalmente, Berguño nos cuenta sobre otra expedición, la del Céleste, "nave armada por el Sieur de Grandsire de Calais y que zarpa de ese puerto con varios antiguos oficiales bonapartistas, que financiaron su expedición, bajo la vigilancia inquieta de las autoridades realistas francesas" (p. 75).

El cuarto capítulo, titulado "La misión Thompson y la expedición de Bellina Skupieski” se centra en el coronel argentino Martín Thompson quien reclutó al oficial polaco Antonio Bellina Skupieski para que integre el cuerpo de oficiales franceses refugiados (p. 79). Este apartado presenta a Bellina como un personaje que creo especulaciones entre los historiadores chilenos, por no tener conocimientos militares y por su falta de modales entre sus colegas (81). El capítulo nos muestra que Bellina solo hacia sembrar dudas entre los oficiales sobre su comportamiento militar. Finalmente, el autor nos explica que Antonio Bellina hará todo lo posible para certificar su rango de coronel mayor, concluyendo que esta “circunstancia se debe quizás más al arribismo que a una lealtad absoluta hacia el emperador” (p. 82).

El quinto capítulo, se titula "Del cruce de los Andes a la batalla de Chacabuco", el autor nos cuenta quienes fueron y que rol tuvieron Antonio Arcos, Bacler d' Albe y Ambrosio Cramer. Para Berguño, Arcos y Bacler d'Alber supieron desempeñarse bien en las funciones militares asignadas otorgando la victoria a los patriotas.

El autor nos explica sobre el reconocimiento que tuvo Antonio Bacler d' Albe por parte del cuerpo de ingenieros argentinos debido a su labor topográfica en el cruce de los Andes. Berguño comenta que "un trabajo titulado Centenario del Ejercito de los Andes, Buenos Aires, 1923, contiene una fotografía de una placa conmemorativa levantada por el Centro Nacional de Ingenieros Argentinos con motivos del cruce de los Andes” (p. 89). 
El sexto capítulo, lleva el título "Brayer, Jefe de Estado Mayor del Ejército Unido de los Andes” (mayo 1817 - marzo 1818). El autor analiza la incorporación de Brayer al Ejército de los Andes en calidad de jefe del Estado Mayor. Ante tal nombramiento plantea la siguiente interrogante, ¿cuáles eran las intenciones de San Martín al ofrecerle este cargo de jefe de Estado Mayor?, Berguño expone la siguiente hipótesis "es posible que San Martín pensara ya en Talcahuano y en la ayuda que podría aportarle un militar experimentado para el asalto a esa plaza” (p. 95). El análisis avanza en las disputas que sostuvo Michel Brayer con Diego Paroissien, "debido a la molestia que sentía porque San Martín lo había defendido” (p. 103).

Como conclusión el autor expone que "la ruptura entre San Martín y el general francés se debió a la incapacidad de Brayer de adaptarse al sistema, a causa del desconocimiento de los planes de campaña de San Martín y del hecho que manifiestamente no contaba con la confianza del jefe” (p. 104).

El séptimo capítulo se denomina "La conspiración de 1817” el autor nos explica la oposición de los hermanos Carrera a las reformas de $\mathrm{O}^{\prime}$ Higgins y a la figura de José de San Martín. Fernando Berguño expone una biografía de Juan José y Luis Carrera por medio de Vicuña Mackenna. Posteriormente Berguño por medio de Francisco Encina, comenta que "Luis Carrera dejó Buenos Aires el 10 de julio de 1817, siguiendo el plan de la conspiración, con el nombre de Leandro Barra, junto a otro joven chileno Juan Felipe Cardenas, de quien se separa en San Juan” (p. 106).

Fernando Berguño cita nuevamente a Encina para contarnos "que la conspiración fue descubierta, con algunos días de intervalo, tanto en Chile como Mendoza” (p. 107).

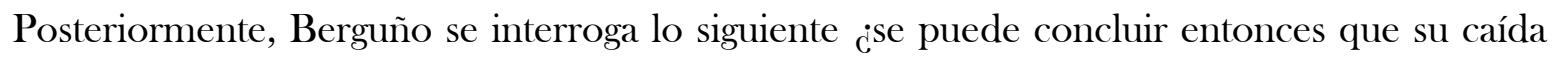
en desgracia se debía únicamente a la falta de disciplina? P. (108). Apoyándose de sus fuentes archivísticas el autor cuenta que "San Martín se quejó de las faltas a la disciplina militar 
atribuidas a Cramer” (p. 108). Para Berguño es "probable que hay una relación causal entre el complot de 1817 y las desgracias de Cramer" (p. 108). El autor expone que "el incidente del duelo tolerado por Cramer no puede ser tomado a la ligera y bastaría de por sí para explicar su traslado a Mendoza” (p. 108). Las fuentes que utilizó para este capítulo provienen del Archivo Nacional, Fondo Claudio Gay, Beauchef: Después de Chacabuco y el Archivo General de la Nación de Buenos Aires, Fondo Guerra, Ejército Unido de los Andes.

El octavo capítulo lleva como título "El asalto a Talcahuano” se analiza a los responsables del fracaso de Talcahuano. Ejemplo de ello, es el comentario de Berguño de quien sería el principal responsable de esta derrota, "a partir de los testimonios de los jefes del Ejército del Sur, se fue creando rápidamente un consenso para acusar al general Brayer, autor del plan de ataque, a quien se quiso también presentar como el promotor de esta ofensiva, con miras a liberar a O’ Higgins, San Martín y Pueyrredón de toda responsabilidad del asunto” (p. 111). El autor se interroga lo siguiente " ¿'se debe acusar a Brayer de haber empujado a los jefes patriotas en busca de gloria personal y contra la opinión de Pueyrredón y de algunos jefes del Ejército del Sur? Hurtado plantea que "la historiografía así lo ha sostenido atribuyendo a Brayer un lugar bastante negativo en la historia” (p. 111).

El noveno capítulo titulado "el desastre de Cancha Rayada” está dedicado a estudiar la participación de Brayer en la caballería patriota y su error táctico a la hora de atacar a los realistas y que según el autor "pudo haberle costado la victoria a los patriotas” (p. 153).

El décimo capítulo se titula “Después de Maipú (abril - mayo 1818)”, resulta ser uno de los más interesantes, puesto que en "este combate tuvieron un gran protagonismo los soldados franceses durante la batalla de Maipú”. Se trata de un análisis del reconocimiento que realizó San Martín a los oficiales franceses por su buena actuación en esta batalla. 
Completa este profuso estudio con el capítulo titulado "Los oficiales franceses en la Guerra Civil de 1829”. El autor estudia la participación de los oficiales franceses durante la Guerra Civil, optando por seguir una ideología constitucional o liberal y "el enfrentamiento de los dos bandos en la batalla de Ochogavía” (p. 271).

De esta forma, la obra de Berguño es una investigación sólida, basada en fuentes originales e inéditas que no han sido trabajadas por la historia nacional. El libro está escrito con una pluma amena, destinada a los historiadores y a los lectores de historia. Para la historiografía chilena es un complemento de lo que hasta ahora se conoce y se puede conocer sobre los soldados de Napoleón en la independencia de Chile.

Jorge Orellana Billiard Estudiante del Magíster en Historia de América Latina Universidad Diego Portales jorgeorellana150@gmail.com 